\title{
Research on Cooperative Management of Supply Chain Culture
}

\author{
Yefu Tang ${ }^{1 \text { a }}$ \\ ${ }^{1}$ Department of Management, Guangdong University of Science \& Technology, Dongguan 523083, \\ Guangdong, China; \\ a76092313@QQ.com
}

Keywords: Supply chain; Synergy; Supply chain culture

\begin{abstract}
This article mainly studies and discusses the cultural synergy of supply chain under the supply chain environment, and puts forward some opinions on the concept, content, status and function of supply chain culture, which has some practical guiding significance for promoting the application of supply chain management in Chinese enterprises.
\end{abstract}

\section{Introduction}

The soft cooperation of the supply chain is to establish a kind of trust partnership between the members of the supply chain. The members can consciously maintain the overall interests of the supply chain, which is the integration of the spirit, culture and ideas, also known as "cultural synergy". The virtuality of the e-commerce environment increases the importance of mutual trust in the supply chain, because the virtual supply chain members are more likely to make short-term speculation, thereby destroying the harmonious relationship of the supply chain. Therefore, it is necessary to establish a supply chain culture to maintain the collaborative operation of the entire supply chain.

\section{Concept of Supply Chain Culture}

At present, the research on Supply Chain Culture in China is still in the exploratory stage, and there is no authoritative definition of supply chain culture. The following scholars put forward their own views on the concept of supply chain culture.

Jin Yong believes that the so-called supply chain culture refers to the alliance cooperation culture ${ }^{[1]}$, which is based on the enterprise culture of the core enterprises in the supply chain to achieve the overall optimal supply chain and to provide satisfactory customer service as the aim, and to form a win-win, mutually beneficial and sharing value concept as the core of the alliance.

Yan Hong believes that after the establishment of the supply chain, to avoid cultural conflicts that may arise from the cultural differences between enterprises, a common culture, that is, supply chain culture, must be formed, that is, supply chain culture, which is the supply chain enterprise in all kinds of activities and results. Values should be accepted and recognized by members. ${ }^{[2]}$.

Ding Weidong believes that supply chain culture is the common values of supply chain enterprises in various activities and results of supply chain enterprises, which are embodied in the supply chain enterprises, the culture of entrepreneur management, the quality of the staff and the entertainment culture, and the social responsibility culture of the enterprise ${ }^{[3]}$.

$\mathrm{Xu}$ Xun believes that supply chain culture is a shared consciousness created by the members of the supply chain as time goes on, as well as intangible relations, systems, skills and knowledge. The process of developing the supply chain partnership gradually between the member enterprises and the supply chain partnership is the process of supply chain culture from breeding to maturity, based on the enterprise culture of the core enterprises in the supply chain, in order to realize the overall optimal supply chain and provide satisfactory customer service as the aim, and to form a win-win, mutually beneficial and shared equivalence principle ${ }^{[4]}$, the core of the alliance co - operation culture.

We prefer Yu Jinyong and $\mathrm{Xu}$ Xun to the view that supply chain culture is a common belief, code 
of conduct and behavior in a long period of cooperation between the various node enterprises on the supply chain. It aims at realizing the overall optimal supply chain and providing satisfactory customer service, with the core of honesty and trustworthiness, emphasizing the sharing of interests and risk sharing as a kind of alliance cooperation culture.

\section{Content of Supply Chain Culture}

The construction of supply chain culture is not achieved overnight. It is pregnant with the formation of supply chain alliance, and in the process of supply chain operation, there is a process of repeated grinding, mutual adaptation and improvement. It needs to be nurtured and cultivated for a long time. Therefore, it is a supply chain management method and management idea to cultivate the concept of joint cooperation in the supply chain. It includes the following four items: ${ }^{[1]:}$

The formation of supply chain culture is based on the enterprise culture of the core enterprises in the supply chain, which is mainly reflected in the radiation and brand effect of the culture of the core enterprise on the culture of non core enterprises. This fusion culture will have the obvious characteristics of the core enterprise's corporate culture and reflect its business philosophy and management ideas.

The idea of establishing the overall optimal supply chain. Under the background of supply chain culture, the best premise for a single enterprise is the optimal supply chain. Therefore, the node enterprises should comply with the maximization of the cooperation interests, especially the core enterprises should focus on the long-term interests, take into account the interests of other node enterprises, so as to strengthen the cooperative relationship and create a good cooperative environment.

To provide satisfactory service to customers as the common goal of supply chain. Therefore, each node enterprise in the supply chain must provide customers with satisfactory products and services as a guide to action, that is to analyze, judge and adjust the production and management activities of each enterprise from the perspective of the customer.

To establish a win-win, mutually beneficial and shared concept. Close cooperation is rooted in the values recognized by all parties in the supply chain of "win-win, mutual benefit and sharing", and establishes a strategic partnership with mutual benefit and complementary advantages to form a competitive advantage group. In this cultural environment, the resources of the supply chain must be rationally allocated and shared. The resources here refer not only to information but also to management, technology and human resources.

\section{The Position of Supply Chain Culture}

Supply chain culture is the basis for the cooperation and communication of each node enterprise. It is the "invisible hand" to resolve the problems and conflicts in the process of cooperation, and also an effective guarantee for consolidating and promoting the cooperation relationship of the supply chain. Supply chain culture plays an important role in the operation and development of supply chain.

Supply chain culture is a pillar to support the sustainable growth of the supply chain. Excellent supply chain culture shows the successful management style, good management situation and noble spirit of supply chain to the society. It is the intangible asset of supply chain. Unlike material resources, the endless supply chain culture is the spiritual pillar to support the sustainable growth of the supply chain. Without culture, no soul can lead the supply chain forward.

Supply chain culture is the key factor determining the rise and fall of supply chain. In terms of the components of the competitiveness of the supply chain, the factors such as image strength and cohesion are becoming more and more important. With the development of science and technology, especially the development of information technology, there are more and more supply chains to produce the same products, sell the same goods and provide similar services. The supply chain customers are very important to identify the supply chain. This requires the supply chain to 
consciously build the image, and then strengthen the cohesion of the supply chain.

Supply chain culture is the main goal of supply chain development strategy. One of the objectives of supply chain development strategy is to establish strategic partnership between nodes. The cultural construction of the supply chain is aimed at shaping the common values and management ideas, promoting the close cooperation of the node enterprises and setting up the overall interests of the individual interests, so as to maintain the overall interests and long-term development of the whole supply chain. Therefore, the construction of supply chain culture is a powerful measure to promote long-term cooperation between nodes.

Supply chain culture resources are the core resources of supply chain. In fact, the supply chain is an organic combination of various tangible and intangible resources, and cultural resources are the most valuable resources, affecting the output and competitive position of the supply chain, and then determining the value of the supply chain. In the era of knowledge economy, the belief and concept of each node in the supply chain is a valuable resource, and this kind of resource plays an irreplaceable role in increasing the survival, development and success of the supply chain.

\section{Conclusion}

In short, with the development of economic globalization, supply chain management has become an inevitable choice for enterprise management in twenty-first Century. It is obvious that the competition in twenty-first Century is no longer the competition between individual enterprises, but the competition between supply chain and supply chain. This is the trend of the times. But there is still a long way to go in our country to promote the idea of supply chain management. The fact is that it is far more important to popularize the theory of supply chain in China. It's much harder to learn. However, the transformation of our business management ideas is necessary. This change is a challenge that has never been faced by the managers of today: they have to face both the challenges of the external environment and the internal organization, and the frequent transformation of the miscellaneous management technology and production methods; on the other hand, they should constantly reflect on them. The shortcomings and inadaptability of the traditional mode, and at the same time, through continuous trial and error to find more effective new strategies.

\section{References}

[1]Y.J.Yu,H. Zhong. On supply chain culture [J]. Journal of Hubei Engineering, 2004 (5),p.64-66.

[2]H.Yan.Strengthen supply chain management and enhance enterprise competitiveness [J]. Business Research, 2004 (12),p.48-50.

[3]W.D.Ding,K.Liu.Analysis of supply chain process transformation mode [J]. Circulation in China, 2003 (8),p.12-15.

[4]X.Xu.Research on the formation mechanism of supply chain culture and its function analysis [J].Shopping Malls Modernization, 2007 (12),p 7-8.

[5] Yu D, Peng L. When does Inferring Reputation Probability Countervail Temptation in Cooperative Behaviors for the Prisoners' Dilemma Game? [J]. Chaos, Solitons \& Fractals, 2015, 78: 238-244. 